\title{
Telling the story of mental health
}

\section{There's a \\ powerful \\ story to be \\ told about \\ mental health, \\ with chapters \\ on the \\ consequences \\ of inadequate \\ care on \\ individual \\ wellbeing and \\ the national \\ economy}

$\mathrm{t}$ is unusual for Foreign Affairs, a magazine published by the United States Council on Foreign Relations in New York, to contain articles on health, but the first issue of 2015 carries an essay (Darkness invisible: the hidden global costs of mental illness) by three distinguished scientists from the National Institute of Mental Health about the hidden costs of mental health. ${ }^{1}$ Based on evidence from a 2010 Harvard University study on the current and future burden of disease, ${ }^{2}$ they state that "the direct economic effects of mental illness (such as spending on care) and the indirect effects (such as lost productivity) already cost the global economy around \$2.5 trillion a year", an amount projected to rise by 2030 "to around $\$ 6$ trillion, in constant dollars - more than heart disease and more than cancer, diabetes, and respiratory diseases combined".

The World Health Organization estimated in 2012 that about a quarter of all time lost to disability is due to mental illness, putting it at the top of the league chart. ${ }^{3}$ Unlike many other chronic illnesses, mental illness frequently strikes the young. Further, of the 800000 people who commit suicide each year, $75 \%$ are in low-income and middle-income countries. ${ }^{4}$

\section{Extraordinary failure}

Yet, the authors of "Darkness invisible" say, the 2010 Harvard report had no impact. In wealthy countries, mental illness is still perceived as an individual or family problem rather than "as a policy challenge with significant economic and political implications". In many low-income and middleincome countries mental care for the mentally ill is seen as an unaffordable luxury. ${ }^{1}$ The authors also point to breakthroughs in therapy, especially new medications and the capacity to communicate using mobile phones, that are now more affordable, yet are frequently overlooked. ${ }^{1}$

So what are we doing? Globally we are spending around \$2 a year per individual on mental health, averaging about 25 cents per person in low-income countries. In Australia in 2004-2005 the average national per capita expenditure on mental health services was $\$ 117 .{ }^{5}$ As we have seen in Australia, the advantages of dismantling mental hospitals that "once oversaw care for the mentally ill", especially those with long-standing severe illness, are accompanied by failures to provide community care for these people. The criminal justice system comes into play by default, in both the acute and long-term management of people with mental illness. In the United States, "30 percent of the country's chronically homeless and more than 20 percent of the people incarcerated ... suffer from a mental disorder". ${ }^{1}$ The scene is dismal in Australia as well.

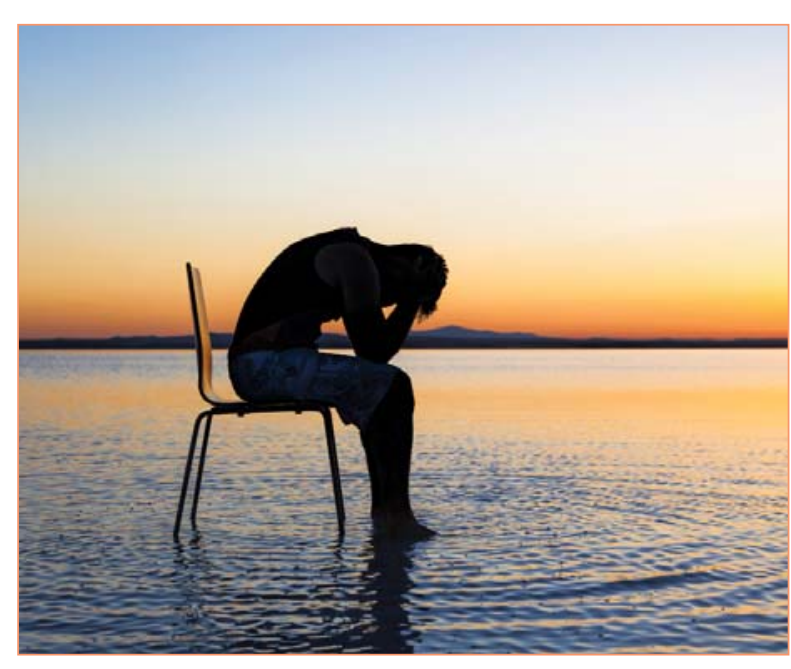

Darkness invisible explores new technologies including using the Internet and mobile devices to provide psychotherapeutic interventions supported by inexpensive generic medications that could be administered by health workers in the vast tracts of the earth where there are very few medical practitioners and no psychiatrists. The authors may well have wondered about the lethargy among the medical profession worldwide in creating opportunities for the training and deployment of more psychiatrists. We don't look good as we pass this mirror. There is no substance to our defence when wealthy communities are well supplied with psychiatrists and psychologists.

\section{A call for better advocacy}

Darkness invisible concludes with a call for mental health advocates to multiply their efforts and "do a better job of explaining to officials and the public the true costs of mental illness", and "win more allies within the medical profession by drawing attention to the fact that improved mental health leads to better overall health". ${ }^{1}$

This call will resonate with those who perceive the lamentable consequences of unexplained political propositions and proposals: bankrupt policy replaced by sound bites and slogans. There's a powerful story to be told about mental health, with chapters on the consequences of inadequate care on individual wellbeing and the national economy.

As a senior business executive put it to me recently, "To succeed, first you must have a convincing story, then good leadership, then the metrics". More light, more storytelling please. 
1 Insel TR, Collins PY, Hyman SE. Darkness invisible: the hidden global costs of mental illness. Foreign Affairs 2015; 9 Feb. http://www.foreignaffairs.com/articles/142490/thomasr-insel-pamela-y-collins-and-steven-e-hyman/darknessinvisible (accessed Feb 2015).

2 Bloom DE, Cafiero ET, Jané-Llopis E, et al. The global economic burden of noncommunicable diseases. Geneva: World Economic Forum, 2011. http://www3.weforum.org/docs/ WEF_Harvard_HE_GlobalEconomicBurdenNonCommunicable Diseases_2011.pdf (accessed Feb 2015).

3 World Health Organization. Health statistics and information systems. Estimates for 2000-2012. Disease burden. YLD estimates, 2000-2012. Global summary estimates. Geneva:
WHO, 2012. http://www.who.int/healthinfo/global_burden_ disease/estimates/en/index2.html (accessed Feb 2015).

4 World Health Organization. Mental health. Suicide data. http://www.who.int/mental_health/prevention/suicide/ suicideprevent/en (accessed Feb 2015).

5 Australian Government Department of Health. National mental health report 2007. Per capita spending by state and territory governments. http://www.health.gov.au/internet/ publications/publishing.nsf/Content/mental-pubs-nreport07-toc mental-pubs-n-report07-c $\sim$ mental-pubs-nreport07-c-5 mental-pubs-n-report07-c-5-per (accessed Feb 2015). 